\title{
Subjective spheres of influence: A perceptual system beyond Mindsponge
}

\author{
Minh-Hoang Nguyen \\ Centre for Interdisciplinary Social Research \\ Phenikaa University \\ Yen Nghia, Ha Dong, Hanoi 100803, Vietnam
}

October 19, 2021

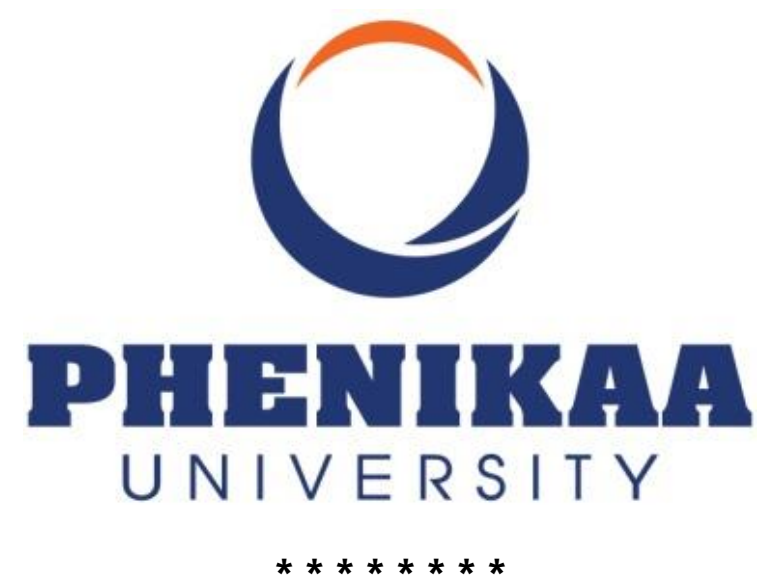

To further explain the fundamental meanings of money [1], I developed a framework regarding an individual's subjective spheres of influence based on the Mindsponge mechanism and Mindsponge-related studies [2-7] to illustrate how individuals perceive what they can influence and what can influence them. In fact, this idea has germinated in my mind since I asked the question: "what are beyond Mindsponge?" [8].

As humans, we live and are attached to multiple systems that might cover or intertwine with the other. Figure 1 illustrates my imagination about the system, with the Earth system being the largest system, represented by the green area. Within the Earth system, there are many social systems that represent different societies with distinct socio-cultural constructs. In the Figure, I only focus on one social system, represented by the blue area (readers can view it as a social system within a country for interpretation), because money is only accepted within a society. The sub-sets of a social system are various institutional systems, represented by yellow areas. Such institutions are founded by a group of people for a certain purpose, like university, enterprise, government, etc.

As for people, there are five types of people:

1) The self (yellow and red bubble)

2) The individuals perceived to be mutually influential with the self (cyan bubbles) 
3) The individuals perceived to be influenced by the self (light red bubbles)

4) The individuals perceived to be able to influence the self (purple bubbles)

5) The individuals perceived to have no interaction with the self (grey bubbles)
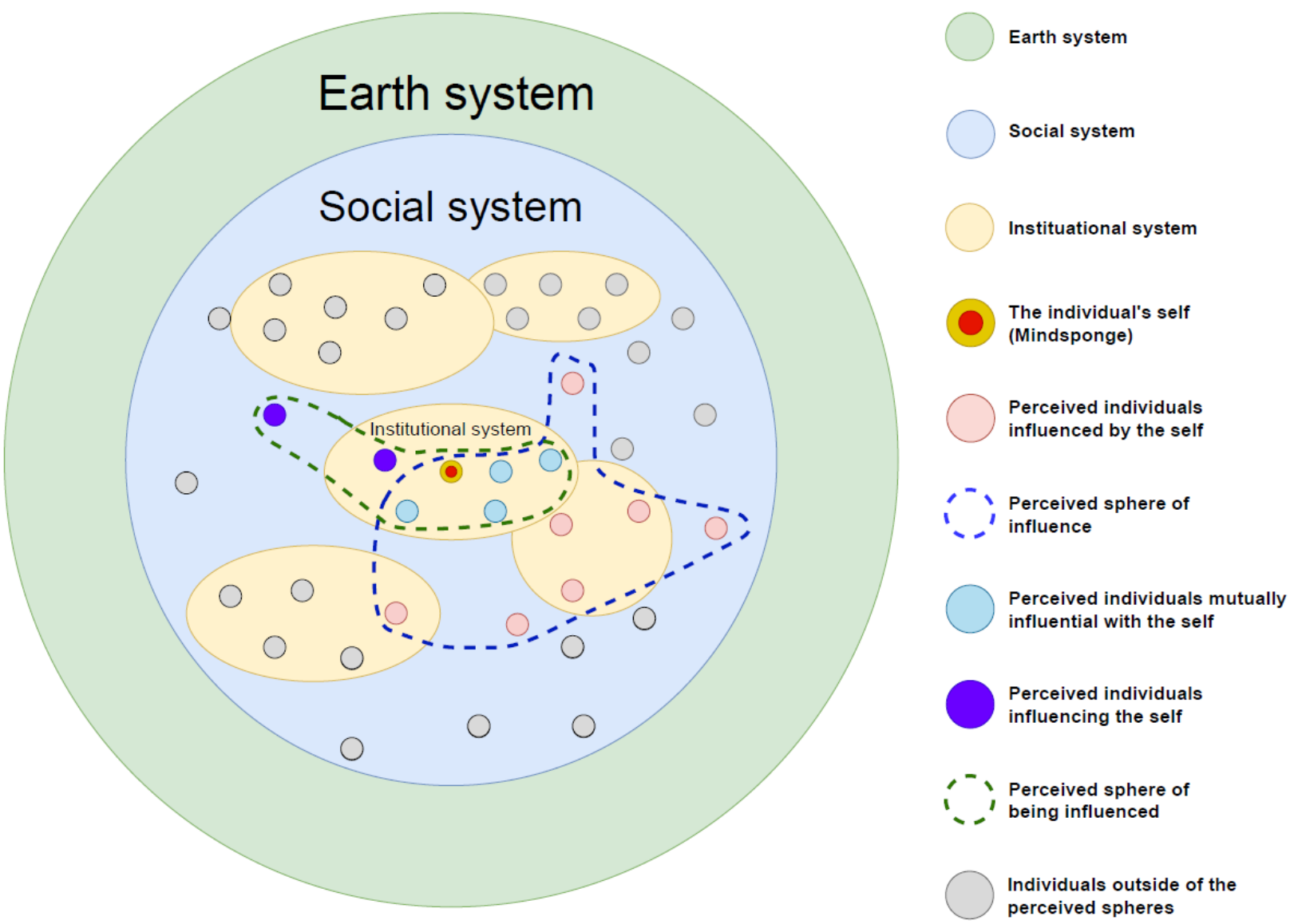

Figure 1: The subjective spheres of influence

Two spheres determine these five types of people: 1) the perceived sphere of influence and 2) the perceived sphere of being influenced. I assume that any individual has an abstract or clear boundary of their sphere of influence (blue dash line) and sphere of being influenced (green dash line). In other words, they have a certain perception about whom they can influence and whom they cannot, and perception about who can influence them and who cannot influence them. The influence here can be interpreted in many ways, including but not limited to physical influences (e.g., materials, money, behaviors), mental influences (e.g., prestige, personality, emotion).

The conceptual development of the subjective spheres of influence framework is valuable because it is expected to help explain the multiplexity of political, economic, socialcultural issues across disciplines. To elaborate, I expect it to help explain how people 
interact with the world around them, how groups are formed, and how societies operate. One of the potential hypotheses derived from this framework is that individuals will think and behave differently towards targets belonging to different perceived spheres of influence and being influenced.

\section{References}

1. Nguyen MH. (2021). What are fundamental meanings of money? OSF Preprints. Retrieved from https://osf.io/yjdpf

2. Vuong QH. (2016). Global mindset as the integration of emerging socio-cultural values through mindsponge processes: A transition economy perspective. In J. Kuada (Ed.), Global Mindsets: Exploration and Perspectives (pp. 123-140). New York: Routledge.

3. Vuong QH, Napier NK. (2015). Acculturation and global mindsponge: An emerging market perspective. International Journal of Intercultural Relations, 49, 354-367. https://doi.org/10.1016/j.ijintrel.2015.06.003

4. Nguyen MH, Le TT, Nguyen HKT, Ho MT, Nguyen HTT, Vuong QH. (2021). Alice in Suicideland: Exploring the suicidal ideation mechanism through the sense of connectedness and help-seeking behaviors. International Journal of Environmental Research and Public Health, 18(7), 3681. https://doi.org/10.3390/ijerph18073681

5. Vuong QH, Nguyen MH, Le TT. (2021). A mindsponge-based investigation into the psycho-religious mechanism behind suicide attacks. Warsaw, Poland: De Gruyter.

6. Vuong $\mathrm{QH}$, Nguyen MH, Le TT. (2021). Home scholarly culture, book selection reason, and academic performance: Pathways to book reading interest among secondary school students. European Journal of Investigation in Health, Psychology and Education, 11(2), 468-495. https://doi.org/10.3390/ejihpe11020034

7. Nguyen MH, Vuong QH, Ho MT, Le TT. (2021). Mindsponge Mechanism. Scholarly Community Encyclopedia. Retrieved from https://encyclopedia.pub/7320

8. Nguyen MH. (2021). What are beyond Mindsponge? OSF Preprints. Retrieved from https://osf.io/c6sdp/ 